\title{
TEORIA E METODOLOGIA EM HISTÓRIA DAS RELIGIÕES NO BRASIL: O ESTADO DA ARTE
}

\author{
Theory and methodology in the History of \\ Religions in Brazil: the state of the art \\ Elton de Oliveira Nunes*
}

\begin{abstract}
RESUMO
Os estudos de religião no Brasil necessitam de uma maior acuidade teórico-metodológica, a despeito de ser nosso país considerado um berço laboratorial de experiências e manifestações religiosas. A área de História sempre foi resistente ao tema e aos estudos sobre as religiões. Tanto o Positivismo acadêmico quanto o Marxismo científico, setores da academia no Brasil, colocam-se avessos e apresentam enorme dificuldade de lidar com o tema: religião. Esta dificuldade explica em parte a rejeição e as preocupações dos estudos de religião.
\end{abstract}

Palavras-chave: religião; História, teoria e metodologia; História das Religiões.

\begin{abstract}
The religion studies in Brazil need to have a better methodological and theoretical precision, in spite of being considered the cradle of religious experiences and manifestations. The History area was always resistant to the theme and to the religious studies. Both academic Positivism and scientific Marxism, important academic areas in Brazil, have been refractory and demonstrate a huge difficulty with the subject. This problem explains partially the rejection and the concerns regarding the religious studies.
\end{abstract}

Key-words: religion; History; theory and methodology; History of Religions.

* Pós-Doutor em História das Religiões pela Pontifícia Universidade Católica de São Paulo. 


\section{Introdução}

O Brasil é um país de proporções continentais ${ }^{1}$, com uma rica e complexa História que o distingue de seus vizinhos na América do Sul ${ }^{2}$. Em sua riqueza e complexidade, encontra-se a formação de sua gente, composta de imigrantes de diversas partes do mundo em uma base étnica matriz portuguesa, africana e indígena. A esses se somam nas mais variadas regiões do país uma amálgama de espanhóis, judeus, árabes, orientais, alemães, italianos, letos, enfim, uma miríade de povos e grupos que contribuíram com suas culturas, olhares e visões de mundo para tornar o Brasil uma terra de toda a gente ${ }^{3}$. Dentre as diversas riquezas que podemos citar, a cosmovisão religiosa, com seus rituais, demonstrações de fé e de pertença mística, está entre as mais complexas heranças e manifestações que podemos atribuir a essa babel étnico-cultural que adentrou a terra brasilis a partir de $1500^{4}$, já encontrando aqui um fluxo contínuo de povos e nações indígenas que circulavam por este imenso território. Essa característica é notada pelo historiador da religião Artur César Isaia ${ }^{5}$ :

Pensar as transformações pelas quais passou o campo religioso brasileiro é pensar, antes de tudo, na extrema complexidade do universo de crenças entre nós. Essa não é uma característica atual. Historicamente já nascemos sob o signo desta complexidade, a partir da experiência ibérica totalmente distante da uniformidade católica com que foi identificada. Para além da ideia de uma monarquia portuguesa, cuja fidelidade à ortodoxia nos textos originais.

1 Os grifos em todas as citações são destaques que queremos ressaltar, não estando destacados

2 Sobre as diferenças entre o Brasil e os demais países da América do Sul, ver: BETHELL, Leslie (Org.). História da América Latina. São Paulo: Edusp, 1997; SANTOS, Luís Cláudio Villafañe. As várias Américas: visões do século XIX. Revista Estudos de História, Franca/SP, v. 10, n. 1, p. 11-28, 2003.

3 Para um panorama sobre esta diversidade, ver: PIERUCCI, Antonio Flavio; PRANDI, Reginaldo. A realidade social das religiões no Brasil. São Paulo: Hucitec, 1996; MENEZES, Renata; TEIXEIRA, Faustino (Orgs.). As religiões no Brasil: continuidades e rupturas. Petrópolis: Vozes, 2006.

4 O Brasil é "descoberto" oficialmente em 1500, com a chegada dos portugueses conduzidos pela esquadra de Pedro Álvares Cabral. Para uma discussão sobre este tema, ver: MOTA, Lourenço Dantas. Introdução ao Brasil. Um banquete no trópico. São Paulo: Ed. Senac, 2001; ODÁLIA, Nilo. As formas do mesmo. Ensaios sobre o pensamento historiográfico de Varnhagen e Oliveira Vianna. São Paulo: Edunesp, 2001; REIS, José Carlos. As identidades do Brasil. De Varnhagen a FHC. Rio de Janeiro: FGV, 2001.

5 ISAIA, Artur César. O campo religioso brasileiro e suas transformações históricas. Revista Brasileira de História das Religiões, ano I, n. 3, p. 95, jan. 2009. 
católica foi a característica dominante, a experiência dos colonizadores já acenava para uma complexidade étnica, cultural, linguística e religiosa notável.

A colonização portuguesa, a partir do padroado real ${ }^{6}$, imprimiu uma base cristã ibérica que acompanhou até os dias atuais os desdobramentos da História do Brasil, vindo a se tornar a maior nação católica do mundo ${ }^{7}$. Os diversos grupos de escravos africanos trazidos ao Brasil em um período de duzentos anos inseriram na matriz brasileira um componente religioso diverso, porém, ligado às tradições espirituais da África, dando origem a hibridações com o catolicismo e com as religiões indígenas, como já dizia Freyre $^{8}$ :

O que se sente em todo esse desadoro de antagonismos são as duas culturas, a europeia e a africana, a católica e a maometana, a dinâmica e a fatalista encontrando-se no português, fazendo dele, de sua vida, de sua moral, de sua economia, de sua arte um regime de influências que se alternam, se equilibram ou se hostilizam. Tomando em conta tais antagonismos de cultura, a flexibilidade, a indecisão, o equilíbrio ou a desarmonia deles resultantes, é que bem se compreende o especialíssimo caráter que tomou a colonização do Brasil, a formação sui generis da sociedade brasileira, igualmente equilibrada nos seus começos e ainda hoje sobre antagonismos.

As imigrações do final do século XVIII introduziram as diversas denominações protestantes ${ }^{9}$, após tentativas de implantação da mesma

6 Para uma definição e aprofundamento do tema, ver: KUHNEN, Alceu. As origens da Igreja no Brasil: 1500 a 1552. Bauru: Edusc, 2005.

7 Os dados sobre esta questão podem ser encontrados em: PALMER, Martin; O'BRIEN Joanne. O Atlas das religiões. São Paulo: Publifolha, 2008. p. 90-94.

8 FREYRE, Gilberto. Casa-grande \& senzala. Rio de Janeiro/São Paulo: Record, 2000. p. 82.

9 Desde a chegada do chamado Protestantismo de Missão, vindo dos EUA, o Brasil vem em um crescendo na influência evangélica. Um dos exemplos mais significativos está na exportação de missionários das diversas denominações protestantes no Brasil: em 1996 eram 1.209; em 1997, este número aumentou para 1.449 missionários no exterior. Partiram para o exterior uma média de 5 missionários por semana, 1 missionário em cada dia útil da semana. Em anos anteriores (1993, 1994, 1995), a média era de 3 missionários por semana. Dados da Associação Brasileira de Missões Transculturais (ABMT). Disponíveis em: <www.infobrasil.org>. Acesso em: 20/06/2005. 
em regiões do Brasil em tempos anteriores ${ }^{10}$. A chegada de imigrantes de diversas etnias na segunda metade do século XIX e início do século XX propiciou a implantação de colônias e grupos religiosos protestantes e católicos, mas também árabes e judeus que puderam manifestar sua religião de forma mais aberta ${ }^{11}$. A vinda de grupos orientais no início do século XX trouxe religiões como a Seicho-No-Ie, Igreja Messiânica, o Budismo, entre outras $^{12}$. As chamadas missões protestantes modernas também implantaram no Brasil, no início do século XX, diversas ramificações que, posteriormente, seriam a base dos chamados Pentecostalismo e Neopentecostalismo ${ }^{13}$. Os novos movimentos religiosos e as mais variadas formas de manifestações religiosas também dão uma conotação diferenciada e própria a um país onde as religiões fazem parte integrante da multiplicidade cultural de um povo multiétnico. Porém, ainda que sejam reconhecidas tais diversidades e complexidades, a História das Religiões, área fundamental para o entendimento e aprofundamento da compreensão da História do Brasil, ainda

10 Diversos pesquisadores dividem a História do Protestantismo no Brasil em quatro grandes blocos ou momentos: o primeiro momento ocorre nos séculos XVI e XVII, com as incursões dos viajantes europeus atrás de terras e especiarias, interessados em estudar a fauna e a flora, os colonizadores, huguenotes da França Antártica (1555) e os calvinistas da Igreja Evangélica Holandesa do Nordeste (1630-1645). O segundo momento ocorre no século XIX, desenvolvido por técnicos, funcionários de missões diplomáticas, marinheiros, colporters. O terceiro momento ocorreu na imigração para o Brasil a partir do século XIX. Esse Protestantismo de Imigração surgiu como uma consequência direta do esforço colonizatório, para cultivo e ocupação dos espaços geográficos brasileiros. O último momento se dá com o estabelecimento protestante no Brasil no período da chamada República Velha, com a chegada de missionários estrangeiros. Dentro desses grandes blocos, os historiadores levantam uma série de ações migratórias, situações de viagem, casos particulares, esporádicos de curta e média duração, que podem ser classificados como tentativas de inserção do protestantismo no grande território brasileiro em formação. Cf. AZEVEDO, Israel Belo de. $A$ celebração do individuo: a formação do pensamento batista brasileiro. Piracicaba: Editora Unimep, 1996. p. 23-34.

11 Temos, nos vários períodos da história do Brasil, situações que conseguiam ultrapassar a barreira imposta pelo catolicismo à presença de outras religiões. Um exemplo é a questão da presença de estrangeiros protestantes que vinham realizar comércio em terras lusas, os escravos africanos ou mesmo os mulçumanos e judeus que aportavam no Brasil. Para uma discussão sobre este tema, ver: SOUZA, Laura de Melo e (Org.). História da vida privada no Brasil: cotidiano e vida privada na América Portuguesa. São Paulo: Cia. das Letras, 1997.

12 Os trabalhos sobre as religiões orientais no Brasil ainda carecem de um aprofundamento maior. Para uma exemplificação dessa situação, ver: ANDRÉ, Richard Gonçalves. Lacunas historiográficas: uma perspectiva sobre as religiões japonesas nos eventos da ABHR e nas Jornadas sobre Alternativas Religiosas na América Latina. Revista Nures, São Paulo: Núcleo de Estudos Religião e Sociedade, n. 10, setembro/dezembro de 2008. Disponível em: <http://www.pucsp.br/revistanures/revista10/Nures10_Andre. pdf $>$. Acesso em: 10/08/2009.

13 Para um aprofundamento sobre os termos e conceituações, cf. MARIANO, Ricardo. Neopentecostais: sociologia do Pentecostalismo no Brasil. São Paulo: Loyola, 2001. 
carece de referenciais teórico-metodológicos que ajudem os pesquisadores brasileiros no entendimento de sua própria gente.

\section{A formação da área de História no Brasil atual}

Uma das grandes dificuldades que a área de História no Brasil enfrenta é dar conta da multiplicidade de objetos que compõem sua área ${ }^{14}$. Ao longo das décadas, a academia brasileira viu-se entre agendas de prioridade sobre identidade, resistência, cultura e desvelamento do povo, das elites, do atraso econômico e social, enfim, uma miríade de temas que foram, por sua vez, tomando espaço, ditando os trabalhos e selecionando os temas ao sabor dos eventos e dos interesses acadêmicos e políticos dominantes. Por sua vez, o Brasil, ou melhor, a academia brasileira, recebeu influxos e influências que determinaram o modo de pensar e de escrever a História de acordo com essa agenda ou apesar dela. Diante disso, refletir sobre o modo como as religiões foram tratadas na área de História no Brasil só pode ser realizado de forma transversal, já que carecemos justamente de pesquisas sobre o tema: religião/religiões. Para tentar dar conta desse tema, apresen-

14 Para uma lista de textos que buscam apresentar a problemática da produção historiográfica brasileira, ver: ABREU, Martha; SOIHET, Rachel (Orgs.). Ensino de História, conceitos, temáticas e metodologia. Rio de Janeiro: Casa da Palavra, 2003; CAPELATO, Maria Helena R. (Coord.). Produção histórica no Brasil, 1985-1994, Catálogo de dissertações e teses dos programas e cursos de pós-graduação em História. 3 v. São Paulo: Xamã, 1995; FICO, Carlos; POLITO, Ronald. A História no Brasil (1980-1989), elementos para uma avaliação historiográfica. Ouro Preto: UFOP, 1992; FICO, Carlos; POLITO, Ronald. Teses e dissertações de História defendidas em 1995. Revista de Estudos Históricos, Rio de Janeiro: FGV/ CPDOC, v. 9, n. 17, 1996; FREITAS, Marcos Cézar de (Org.). Historiografia brasileira em perspectiva. São Paulo: Contexto, 2001; LAPA, J. R. do Amaral. História e historiografia, Brasil pós-64. Rio de Janeiro: Paz e Terra, 1985; NOVAIS, Fernando A. A Universidade e a pesquisa histórica, apontamentos. Revista de Estudos Avançados, São Paulo: USP, v. 4, n. 8, jan./abr. 1990; SAMARA, Eni de Mesquita. Historiografia brasileira em debates, olhares, recortes e tendências. São Paulo: Hermanitas/FFLCH-USP, 2002; WEHLING, Arno et al. Tendências da historiografia brasileira contemporânea, uma aproximação preliminar. In: CONGRESSO DA ASSOCIAÇÃO IBEROAMERICANA DE ACADEMIAS DE HISTÓRIA, 7., 2000. Anais... Rio de Janeiro: Instituto Histórico e Geográfico Brasileiro, 2000; BURMESTER, Ana Maria. A desconstrução do Discurso Histórico. A historiografia brasileira dos anos 70. Curitiba: Aos Quatro Ventos, 1998; CARDOSO, Ciro Flamarion; VAINFAS, Ronaldo (Orgs.). Domínios da História. Ensaios sobre teoria e metodologia. Rio de Janeiro: Campus, 1997; FREITAS, Marcos César (Org.). Historiografia Brasileira em Perspectiva. São Paulo: Contexto, 1998. 
tamos quatro grandes tendências ou escolas que influenciaram de forma decisiva as pesquisas no campo de História do Brasil moderno.

A primeira, fruto da herança positivista e liberal que marcou a transição dos estudos históricos e sociais desde a República, como apontam Refkalefsky e Patriota ${ }^{15}$ :

A temática sobre Religião e Religiosidade na Comunicação Social ainda não recebeu da comunidade acadêmica brasileira - apesar de importantes estudos pioneiros - a relevância necessária. Em primeiro lugar, devido à ênfase positivista na formação da universidade brasileira, como relacionou Antônio Gouveia de Mendonça. Por conta deste enfoque, somente em 1999 os cursos de Teologia ganharam status de bacharelado perante o MEC. Além disso, algumas áreas de conhecimento acadêmico sobre Ciência da Religião - e variações, como Religiões Comparadas ou Esoterologia - apresentam produção científica pouco significativa no país.

Refletindo sobre a questão positivista na academia brasileira, Fonseca indica que, durante o período da ditadura militar no Brasil, intensificou-se a presença do Positivismo nos fundamentos teóricos da História ${ }^{16}$ :

[...] a História tradicional positivista adequava-se aos interesses do Estado autoritário, na medida em que apresenta o quadro de uma sociedade hierarquizada, cuja vida é conduzida de cima para baixo e onde a ordem é máxima a ser seguida pelos seus membros. Sem espaço para a interpretação crítica, não há como instrumentalizar o indivíduo para a interpretação e a análise crítica.

A segunda tendência vem do Marxismo Clássico, na explicação sobre o atraso brasileiro e sua dependência econômica na vertente aberta

15 REFKALEFSKY, Eduardo; PATRIOTA, Karla Regina Macena Pereira. Marketing e Religião: o mercado da fé no Brasil. In: INTERCOM - SOCIEDADE BRASILEIRA DE ESTUDOS INTERDISCIPLINARES DA COMUNICAÇÃO, 29., Brasília, 6 a 9 de setembro de 2006. Anais... Brasília, UnB, 2006. p. 2. 1995. p. 31.

16 FONSECA, Selva Guimarães Fonseca. Caminhos da história ensinada. São Paulo: Papirus, 
por Caio Prado Júnior, Celso Furtado, Fernando Novais, Antônio Barros de Castro, Ciro Flamarion Cardoso e Jacob Gorender ${ }^{17}$. Pode-se observar essa tendência no texto de Karina Kosicki Bellotti, quando a mesma faz referência aos trabalhos na área de História da década de $1970^{18}$ :

Pode-se observar essa premissa no trabalho de Anita Novinsky. Apesar de publicado em 1972, consumiu dez anos de pesquisas, em uma época em que as tendências historiográficas não elegiam as religiões como um tema relevante no Brasil. A história social de inspiração marxista predominava na academia brasileira desde a década de 40 e, após o golpe militar de 1964, muitos historiadores e cientistas sociais sentiram-se incumbidos de fazer frente à ditadura, com trabalhos ligados à política e à economia.

A terceira, na influência da Escola dos Annales ${ }^{19}$, trazida para o Brasil na formação da Universidade de São Paulo (USP). A quarta e última, com a Escola Marxista Inglesa ${ }^{20}$ e os estudos culturais, oriundos das interpretações da História com Eric Hobsbawm, Christopher Hill, Rodney Hilton, Thompson, Royden Harrison, entre outros. Todas essas influências marcaram profundamente os estudos brasileiros e o tratamento dado ao tema das religiões está diretamente ligado a essas correntes e escolas. Essa trajetória é destacada por Karina Kosicki Bellotti ${ }^{21}$, que apresenta, através da análise de três historiadoras de referência, as diversas tendências da

17 Cabe citar os estudos empreendidos por Cardoso e Gorender sobre os modos de produção; das relações entre as economias coloniais e o capitalismo em formação, como é o caso de Novais, ou os trabalhos sobre as formas de riqueza e acumulação nas obras de Castro e Fragoso e Florentino. Cf. CARDOSO, C. F. Agricultura, escravidão e capitalismo. Petrópolis: Vozes, 1979; NOVAIS, F. A. Portugal e Brasil na crise do antigo sistema colonial (1777-1808). São Paulo: Hucitec, 1978; GORENDER, J. $O$ escravismo colonial. São Paulo: Ática, 1985; FRAGOSO, J.; FLORENTINO, M. O arcaísmo como projeto. Rio de Janeiro: Diadorim, 1993.

18 BELLOTTI, Karina Kosicki. Identidade, alteridade e religião na historiografia colonial. Revista de História e Estudos Culturais, ano VII, n. 3, dez. 2010. Disponível em: <http://www.revistafenix. pro.br/vol2karina.php>.

19 Para um aprofundamento sobre a influência francesa na historiografia brasileira, ver: SILVA, Rodrigo Forastieri da. História da Historiografia. São Paulo: EDUSC, 2001.

20 Para um aprofundamento sobre o impacto e repercussões da Escola Inglesa na historiografia brasileira, ver: SADER, Emir. A vingança da História. São Paulo: Boitempo Editorial, 2003; SILVA, Maria M. R. Souza. Breves reflexões sobre a historiografia inglesa: o grupo da revista Past \& Present. Revista de História. São Paulo: Unicamp, 2000.

21 Cf. BELLOTTI, Karina Kosicki. Identidade, alteridade e religião na historiografia colonial. Fênix - Revista de História e Estudos Culturais, UFU, ano II, n. 2, jan.-mar. 2005. 
Nova História: a partir das pesquisas sobre religião de Anita Novinsky, que trabalha nas décadas de 70 e 80 a História das mentalidades; de Laura de Mello e Souza, publicando seus textos sobre religiosidades no Brasil colonial nas décadas de 80 e 90, seguindo as teorizações de LeGoff, LeRoi, Carlo Ginzburg, Keith Thomas e Jean Delumeau; e, por fim, de Mariza Soares, que publica nas décadas de 1990 e 2000 , seguindo os estudos culturais presentes nas teorizações dos marxistas ingleses.

O que se verifica, entretanto, é que, apesar de os estudos sobre a religião alcançarem no fim do século XX uma posição crescente e mesmo privilegiada, os historiadores no Brasil não têm, no atual aporte metodológico, centrado em algumas escolas, as condições de exploração dessa riqueza e diversidade ${ }^{22}$. Essa dificuldade é apontada por Albuquerque ${ }^{23}$ :

Seria preciso um outro lugar para examinar a produção brasileira dos historiadores voltada para a religião. Antropólogos e sociólogos, em várias oportunidades, realizaram balanços sobre seus estudos sobre as religiões. Os historiadores estão ausentes nestas recensões. Ademais, ao elaborarem o mapeamento do próprio campo, os historiadores silenciam sobre a religião, a história da Igreja e da religiosidade popular, apesar de comparecerem, nestes levantamentos, temáticas renovadas na historiografia.

Essa situação se constata por uma série de fatores históricos e de escolhas metodológicas a partir das influências que a Academia brasileira sofreu ao longo de sua formação e consolidação. Sobre os problemas do modelo de formação dos historiadores e dos pesquisadores na área de História no Brasil, Falcon comenta ${ }^{24}$ :

Nossos historiadores têm por hábito analisar a produção historiográfica contemporânea no Brasil, a partir de 1970/1, isto é, da chamada institucionalização da pós-graduação entre

22 Como bem constata Albuquerque no seu balanço da historiografia brasileira sobre os estudos de religião. Cf. ALBUQUERQUE, Eduardo Bastos. A História das Religiões. In: USARSKI, Frank (Org.). O espectro disciplinar da Ciência da Religião. São Paulo: Paulinas, 2007. p. 19-52.

23 ALBUQUERQUE, Eduardo Bastos. A História das Religiões. Op. cit., p. 48.

24 FALCON, Francisco José Calazans. A cadeira de História Moderna e Contemporânea e o ensino e a pesquisa histórica na Fnfi-Ub. In: MATTOS, Ilmar Rohloff de (Org.). História do ensino da História no Brasil. Rio de Janeiro: Access, 1998. p. 112-113. 
nós. [...] Mais importante, porém, é que estavam postas em discussão concepções diversas, baseadas em modelos europeus e no norte-americano, além de uma tradição já consolidada e respeitável que era a da USP. Mais que fruto deste debate, o modelo adotado foi legislado e imposto como o único legalmente válido, sem deixar espaços para outras experiências. Ironicamente, internalizou-se de tal maneira o modelo que raros se dão conta efetivamente do quanto ele predeterminou as características da pós-graduação entre nós, aí incluídos muitos dos seus problemas.

Entre os problemas do modelo adotado, podemos elencar as religiões como um deles. Seguindo uma lógica de centralidade de formação, a área de História teve profunda influência na estrutura estabelecida no curso de Pós-Graduação da USP ${ }^{25}$, que não apenas formou, mas estruturou os diversos cursos de formação de professores e pesquisadores no Brasil. Sobre esse ponto, é esclarecedora a opinião de Malerba ${ }^{26}$ :

No plano historiográfico, é sabido que Lucien Febvre sempre manifestou fascínio por esse campo privilegiado de estudos que era a América do Sul. E, quando os próprios Annales tinham uma presença apenas marginal no cenário historiográfico francês, desde muito cedo começam a entabular vínculos importantes entre os Annales e alguns expoentes da historiografia e das ciências sociais na América Latina. Exemplo notório dessa aproximação foi a presença, entre 1935 e 1937, de Fernand Braudel como um dos primeiros professores da cátedra de história das civilizações da recém-fundada Faculdade de Filosofia, Ciências Sociais e Letras da Universidade de São Paulo. A presença de Braudel deitou profundas raízes na historiografia brasileira. O Programa de Pós-Graduação da USP foi o pioneiro no Brasil, uma verdadeira matriz que formou quase a totalidade dos historiadores brasileiros.

25 Para Campos, "a fundação da Universidade de São Paulo (USP), em 1934, com a Faculdade de Filosofia, Ciências e Letras, e dentro dela a Seção de História (hoje departamento de História), é o marco inicial de uma formação eminentemente acadêmica no campo da História no Brasil". Op. cit. CAMPOS, Pedro M. de. O estudo da História na Faculdade de Filosofia, Ciências e Letras da Universidade de São Paulo. Revista de História, São Paulo: USP, n. 8, p. 491-503, 1954.

26 MALERBA, Jurandir. A História na América Latina: ensaio de crítica historiográfica. Rio de Janeiro: FGV Editora, 2009. p. 67. 
Para Emília Viotti da Costa, essa influência já perpassava a própria cultura brasileira desde o século $\mathrm{XIX}^{27}$ :

\begin{abstract}
$\mathrm{Na}$ história da cultura brasileira há um momento em que ela passa direta e nitidamente a sofrer influência da cultura francesa. Essa época é o século XIX. Durante anos e anos, inúmeros traços foram acrescentados à vida brasileira graças aos contatos com homens, costumes, ideias e coisas de procedência francesa. Os velhos jornais, o relato de viajantes que percorreram o país nesse período e as memórias da época, oferecem excelente documentação que atesta a importância dessa influência, consignando, por vezes, choques com outras, sobretudo a inglesa.
\end{abstract}

Desse modo, a influência francesa na área de História e na formação dos historiadores no Brasil se fez sentir de forma decisiva. O próprio projeto de fundação da $\mathrm{USP}^{28}$ e, mais especificamente, da Faculdade de Filosofia, Ciências e Letras (FFCL), foi concebido pelos fundadores como um órgão prioritário para a constituição de uma unidade de pensamento nacional. Georges Dumas, professor de Sociologia da Universidade de Sorbonne, foi a ponte para trazer ao Brasil, anualmente, professores de várias universidades francesas, tais como: Roger Bastide, Claude Lèvi-Strauss, Paul Arbousse-Bastide e Fernand Braudel. Os mesmos influenciaram decisivamente na consolidação das Ciências Humanas na USP. Esse modelo de ensino seguia os modelos alemão e francês (influenciado pelo modelo napoleônico). A estrutura de formação das instituições brasileiras de ensino superior vinha recebendo críticas desde a época imperial e líderes como Fernando de Azevedo defendiam um modelo que seguisse o modelo europeu, mais precisamente o francês e o alemão ${ }^{29}$ :

27 DA COSTA, Emília Viotti. Alguns aspectos da influência francesa em São Paulo na segunda metade do século XIX. Revista de História. São Paulo: USP, 2000. p. 142-143.

28 O plano de fundação da USP foi redigido por Fernando de Azevedo, a pedido de Júlio de Mesquita Filho e Armando de Salles Oliveira. O projeto de fundação da USP foi assinado por Fernando de Azevedo, Vicente Rao, Júlio de Mesquita Filho; Fonseca Telles e Teodoro Ramos, Raul Briquet e André Dreyfus, Rocha Lima e A. Bittencourt e Almeida Júnior. In: CARDOSO, Irene de A. R. A universidade da comunhão paulista. São Paulo: Autores Associados/Cortez, 1982. p. 96.

29 Para um aprofundamento sobre a influência da França na formação da Universidade de São Paulo, ver: CAPELATO, Maria Helena; PRADO, Maria Ligia. A l'origine de la collaboration universitaire franco-brésilienne: une mission française à la Faculté de Philosophie de São Paulo. Revue Préfaces, Paris, ano 14, p. 100-105, juillet/septembre, 1989. 
A adoção do modelo francês (tanto Mesquita Filho como Duarte tinham estudado em Paris) implicou que os professores estrangeiros eram vistos não apenas como cientistas e especialistas, mas como intelectuais, fundadores de uma nova intelligentsia cosmopolita. De fato, eram percebidos como tal; suas palavras e realizações estavam sempre em destaque, ao que muito contribuiu a cobertura permanente do influente jornal de Júlio de Mesquita. Com exceção dos franceses, porém, os professores estrangeiros nunca assumiram eles próprios esse papel. [...] Da sua parte, os cientistas sociais adotaram uma abordagem mais à la francesa, de orientação marxista, que parecia fornecer respostas aos problemas socioeconômicos do país e apontar o caminho para as soluções.

As preocupações eram a formação das elites, a pesquisa e a unidade entre ensino e investigação científica com ênfase na formação geral e humanista, autonomia relativa da universidade diante do Estado, concepção idealista e não pragmática de universidade, com estreita ligação entre a formação das elites dirigentes e o projeto de nacionalidade ${ }^{30}$. Segundo Capelato, Glazer e Ferlini ${ }^{31}$ :

Os professores vindos da França, para o primeiro semestre do curso, permaneceram pouco tempo, sendo substituídos por outros, também franceses, em início de carreira, que ficaram, no mínimo, dois anos. Alguns estabeleceram relações mais estreitas com o país, prolongando sua permanência. Formaram discípulos, com os quais dividiram a docência. No plano intelectual, os franceses introduziram a preocupação com a orientação metodológica e com o rigor da análise documental, iniciando uma relação com temas da historiografia francesa, especialmente a dos Annales, vanguarda na época.

Ao longo do tempo, a concepção alemã sofreu uma série de modificações e desvios, em detrimento ao modelo pragmatista norte-americano

30 Tal ligação fica evidente no Decreto $n^{\circ} 6.283$, de 25 de janeiro de 1934, que institui as bases da fundação da universidade. In: FÁVERO, Maria de Lourdes de A. Universidade \& poder; análise crítica/fundamentos históricos: 1930-45. Rio de Janeiro: Achiamé, 1980. p. 179.

31 CAPELATO, Maria Helena Rolim; GLEZER, Raquel; FERLINI, Vera Lúcia Amaral. A escola uspiana de História. Revista de Estudos Avançados, São Paulo: Scielo, v. 8, n. 22, dez. 1994. Disponível em: <http://www.scielo.br/scielo.php?pid=S0103-40141994000300044\&script=sci_arttext >. Acesso em: 10/08/2009. 
de universidade. $\mathrm{O}$ modelo norte-americano influenciou não apenas as universidades brasileiras, mas também as universidades latino-americanas ${ }^{32}$. No Brasil, essa concepção será amplamente difundida a partir da Reforma Universitária de $1968^{33}$, atingindo a estrutura organizacional e as finalidades de todas as universidades. Porém, se as reformas atingiram o campo político e estrutural, a visão sobre as religiões permaneceu inalterada. As religiões continuavam a ser consideradas como etapas a serem vencidas ou mesmo meros detalhes explicativos do componente econômico ou de dominação colonizadora $^{34}$. O fato é que a visão negativa sobre as religiões no Brasil é de longa data. Desde a República, as diversas religiões eram entendidas como parte da ideia de atraso cultural do povo brasileiro ou mesmo uma excentricidade regional, como nos relata, a título de ilustração, a obra de Freyre $^{35}$.

É assim que a noção de caiporismo, tão ligado à vida psíquica do brasileiro de hoje, deriva-se da crença ameríndia no gênio agourento do caipora; este era um caboclinho nu, andando de uma banda só, e que quando aparecia aos grandes era sinal certo de desgraça. Sumiu-se o caipora, deixando em seu lugar o caiporismo, do mesmo modo que desapareceram os pajés,

32 MALERBA, Jurandir. A História na América Latina..., op. cit., p. 49-91.

33 Em 1968, foi instituído o Grupo de Trabalho encarregado de estudar a reforma da Universidade brasileira, constituído por representantes dos Ministérios da Educação e Planejamento, do Conselho Federal de Educação e do Congresso. Eram afirmadas no novo projeto político em implantação as linhas gerais confirmadas pela lei 5.540, a forma ideal de organização do ensino superior, na sua tríplice função de ensino, pesquisa e extensão, enfatizando-se a indissolubilidade entre essas funções, particularmente entre ensino e pesquisa. Para um aprofundamento sobre este tema, ver: CUNHA, Luiz Antonio. Ensino superior e universidade no Brasil. In: VEIGA, Cynthia Greive; LOPES, Eliane Marta Teixeira; FARIA FILHO, Luciano Mendes (Orgs.). 500 anos de educação no Brasil. Belo Horizonte: Autêntica, 2000; GUSSO, Divonzir Arthur et al. A pós-graduação na América Latina: o caso brasileiro. Brasília: UNESCO/CRESALC/ MEC/SESU/CAPES, 1985; SCHARTZMAN, Simon (Org.). Universidades e instituições científicas no Brasil. Brasília: CNPq, 1986.

34 Verdade é que algumas religiões eram tratadas de forma diferenciada dentro da academia brasileira. Principalmente pelo viés da ideia de resistência popular, as religiões afro tiveram um tratamento diferenciado do cristianismo. O Protestantismo e, em especial, o Pentecostalismo, parecem ter o seu lugar garantido nos estudos históricos e sociológicos sob via negativa. Para um debate sobre essa redução nos estudos sobre o Protestantismo brasileiro, ver: GIUMBELLI, Emerson. A vontade do saber: terminologias e classificações sobre o Protestantismo brasileiro. In: Revista Religião e Sociedade, Rio de Janeiro: ISER, v. 21, n. 1, p. 111-112, 2001.

35 FREYRE, Gilberto. Casa-grande \& senzala. Rio de Janeiro/São Paulo: Record, 2000. p. 165 . 
deixando atrás de si primeiro as "santidades" do século XVI, depois várias formas de terapêutica e de animismo, muitas delas hoje incorporadas, junto com sobrevivências de magia ou de religião africana, ao baixo espiritismo, que tanta concorrência à medicina $\mathrm{e}$ ao exorcismo dos padres, nas primeiras cidades $\mathrm{e}$ por todo o interior do Brasil.

Para tanto, a leitura teórico-metodológica dos Annales foi fundamental para a área de História na medida em que os estudos sobre as religiões poderiam ser tratados pela via da despersonalização do objeto. Os Annales, a partir das análises quantitativas e séries estatísticas, no seu primeiro período, baseavam-se em paradigmas compartilhados pelas ciências econômicas e sociais. Mesmo com a mudança para a História das Mentalidades, nos anos 70, trazendo novas considerações acerca dos objetos de estudo e aproximando-se de algumas técnicas da análise semântica e linguística, a História das Mentalidades não rompia com o aparato utilizado pela historiografia econômica e social, pois recorria às ferramentas estatísticas da Sociologia e da Economia. Dessa forma, a religião continuava dentro de uma lógica apoiada pelas mesmas técnicas positivistas de negação de uma autonomia ou constituição como um objeto histórico. Para os Annales, a temática religiosa seguia a interpretação Durkheiminiana de representação social. Um dos exemplos desse posicionamento é a obra de Marc Bloch, Os reis taumaturgos. As propostas de Bloch para a leitura da História a partir da análise de um tema religioso como representação política e social marcaram os Annales e foram incorporadas na metodologia de leitura da História dos temas religiosos no Brasil. Ao propor novos questionamentos em Os reis taumaturgos, Bloch dá as condições de se ler a religião como uma janela para a sociedade. Claramente na esteira da leitura durkheimiana, o sagrado é definido como uma representação da sociedade. Dessa forma, podemos afirmar que a própria formação do historiador, seja ele pesquisador ou professor, no Brasil, está eivada da influência de alguns centros de formação que foram privilegiados. Silva constata isso quando diz que ${ }^{36}$ :

36 SILVA, Kalina Vanderlei. A ficção latino-americana e a formação do professor de História: uma experiência conjugada com a prática de pesquisa histórica. In: ENCONTRO INTERNACIONAL DA ANPHLAC, 7., Campinas. Anais eletrônicos... Campinas: ANPHLAC, 2006. p. 02. 
A grande influência das escolas historiográficas francesas na formação dos historiadores brasileiros garantiu que, a partir do trabalho de historiadores como Georges Duby, a literatura fosse utilizada como fonte histórica. E as novas influências da Nova História Cultural, ou seja, de métodos e técnicas da Linguística, da Teoria Literária e da Antropologia, têm garantido a continuidade da relação entre Literatura e História. Em vista das influências desta formação sobre os historiadores brasileiros, e pelo etnocentrismo ainda presente tanto no imaginário coletivo brasileiro quanto na indústria editorial e nos currículos de História dos ensinos fundamental, médio e superior do Brasil, as obras dos historiadores franceses, assim como a própria História da França, ocupam grande espaço tanto na prateleira das livrarias quanto em nossas salas de aula.

Assim, podemos afirmar que a constituição de alguns centros de influência privilegiaram olhares e objetos e relegaram outros. Um desses objetos relegados foi a religião/religiões como objeto histórico a ser investigado. Apesar disso, as abordagens sobre a religião no Brasil continuam a crescer, seja pela quantidade de fontes e acervos inéditos ou não totalmente explorados, seja pelo crescente interesse da nova geração que busca por outros objetos, outras fontes e outros interesses ${ }^{37}$. Sobre esse ponto, já nos alertava Freitas, quando disse $q^{3} \mathrm{e}^{38}$ :

Para investigar a historiografia brasileira, a distância de posicionamentos como historiador do micro ou do historiador do macro é necessária, por assim dizer, para surpreender os olhares sobre as fontes, não olvidando que, muitas vezes, no caso da pesquisa histórica a fonte faz o olhar de quem olha. É preciso também ir além: perceber a emergência constante de novas fontes para novos olhares.

Faz-se necessário, portanto, ampliar o leque teórico-metodológico na área de História para dar conta dos estudos sobre as religiões no Brasil.

37 Sobre este ponto, é importante salientar a obra Historiografia brasileira em perspectiva, organizada pela Editora Contexto, em 2005, que procurava justamente apontar um balanço da historiografia brasileira, suas influências e mesmo seus limites teóricos. Cf. FREITAS, Marcos Cezar (Org.). Historiografia brasileira em perspectiva. São Paulo, Contexto, 2005.

38 FREITAS, Marcos Cezar (Org.). Historiografia brasileira em perspectiva, op. cit., p. 12. 
Em um levantamento realizado sobre os Programas de Pós-Graduação na área de História, verificou-se que, dos cinquenta e dois programas, apenas dois têm a disciplina de História das Religiões em sua matriz curricular ${ }^{39}$. Esse dado demonstra que a religião não é tratada devidamente pela área de História no Brasil. Ainda assim, os historiadores das religiões sempre buscaram espaços institucionais para divulgação de sua produção. Um desses espaços foi a criação da Associação Brasileira de História das Religiões ${ }^{40}$ (ABHR), que reunia historiadores, antropólogos, cientistas da religião e sociólogos para produzir e refletir sobre os trabalhos que estes pesquisadores estavam realizando. Porém, especificamente em relação aos historiadores, persistiam e persistem as dificuldades em relação às teorias de abordagem, como bem nos demonstra Watanabe ${ }^{41}$ :

No caso dos historiadores, ao analisarmos a seleção dos objetos, fontes, problemas, e a preferência teórica dos professores fundadores desse grupo no Brasil, apontamos para a chamada Nova História Cultural francesa. A primeira pesquisadora a expor essa aproximação da História Cultural e o estudo dos evangélicos brasileiros foi Karina Bellotti. No seu texto "Mídia, religião e História Cultural" ${ }^{42}$, a autora fez um levantamento sobre a consolidação da chamada História Cultural Francesa na academia. Incitada pelas possibilidades e limites dessa metodologia, problematizou uma história estritamente marxista ou demasiadamente positivista no estudo da religião.

Outras iniciativas foram constituídas depois da criação da ABHR, como o GT de História das Religiões da Associação Nacional de História张,

39 AUTOR, 2009. Baseado em: CAPES - 2007. Disponível em: <www.capes.org.br >. Acesso em: 10/06/2009.

40 AAssociação foi criada em 1999 por um grupo de professores historiadores e cientistas da religião para suprir um espaço de diálogo e representação dos estudiosos em religião que não encontravam guarida nos meios acadêmicos para seus objetos de pesquisa. Para um aprofundamento sobre a história da ABHR, ver: <www.abhr.org.br>.

41 WATANABE, Tiago Hideo Barbosa. Análise das comunicações do grupo de pesquisa protestantismo e pentecostalismos nos simpósios da ABHR (Associação Brasileira de História das Religiões). In: ENCONTRO DA ABHR, 2008. Anais... Assis/SP: ABHR, 2008.

42 BELLOTTI, Karina Kosicki. Mídia, religião e História Cultural. Revista de Estudos da Religião, n. 4, 2004.

43 Segundo o site da ANPUH, em 19 de outubro de 1961 foi fundada, na cidade de Marília, Estado de São Paulo, a Associação Nacional dos Professores Universitários de História, ANPUH. A entidade 
mas ainda buscando agregar e difundir a importância do estudo das religiões no campo da História e, especificamente, entre os historiadores brasileiros. Tudo isso vem demonstrar a necessidade de ampliação do leque teórico-metodológico para tratar do tema religião/religiões no Brasil.

\section{Considerações finais}

Se outras áreas têm alcançado cada vez mais espaço na historiografia no Brasil, como podemos citar os estudos de gênero, a Micro-História e o Neo-Historicismo, em relação aos estudos históricos das religiões existe a necessidade de diálogo com outros centros de teorização. É imprescindível essa abertura, dado que o Brasil figura entre os países com uma grande riqueza em relação aos fenômenos religiosos que estão presentes na mídia e no cotidiano, nas diversas regiões que compõem este grande país. Um desses centros é a Escola Italiana de História das Religiões. Apesar de seu grande alcance e renome internacional, ainda não há textos dessa escola traduzidos e publicados aqui, apenas citações esparsas, algumas referências de pesquisadores e artigos em revistas especializadas que não chegam a penetrar no dia a dia da academia e, por isso, permanecem desconhecidos da maioria dos historiadores.

Recebido em dezembro de 2010.

Aprovado em abril de 2011.

trazia na sua fundação a aspiração da profissionalização do ensino e da pesquisa na área de história, opondo-se de certa forma à tradição de uma historiografia não acadêmica e autodidata ainda amplamente majoritária à época. Atuando desde seu aparecimento no ambiente profissional da graduação e da pós-graduação em história, a ANPUH foi aos poucos ampliando sua base de associados, passando a incluir professores dos ensinos fundamental e médio, e, mais recentemente, profissionais atuantes nos arquivos públicos e privados e em instituições de patrimônio e memória espalhadas por todo o país. O quadro atual de associados da ANPUH reflete a diversidade de espaços de trabalho hoje ocupados pelos historiadores em nossa sociedade. A abertura da entidade ao conjunto dos profissionais de história levou também à mudança do nome que, a partir de 1993, passou a se chamar Associação Nacional de História, preservando-se, contudo, o acrônimo que a identifica há mais de 40 anos. Cf. <http://www.anpuh.org/conteudo/view?ID_CONTEUDO=1>. Acesso em: 10/08/2009. 